\title{
perifèria
}

Número 20 (1), junio 2015

http://revistes.uab.cat/periferia

\section{Los postulantes a adopción: biología, deseos y afectos para definir las fronteras de la familia}

\author{
Mariela Pena ${ }^{1}$ \\ CONICET/UBA/IIEGE/CAF
}

DOI: http://dx.doi.org/10.5565/rev/periferia.446

\section{Resumen}

En este artículo abordamos las dificultades, motivaciones y procesos recorridos por quienes se postulan para adoptar en Buenos Aires mediante su inscripción en lo que suele conocerse como el "circuito legal". Exploramos las construcciones y reformulaciones que estas mujeres y varones realizan en torno a sus ideas sobre la familia, las conexiones biológicas o sociales y la adopción, durante el período que transcurre entre los inicios de sus proyectos de convertirse en madres y padres frecuentemente mediante la procreación biológica y con la asistencia de tecnologías reproductivas (NTR) - hasta que optan por la adopción, en muchos casos frente a los conflictos sufridos con los tratamientos médicos o debido a la infertilidad involuntaria. Partimos de la perspectiva teórica de la antropología del parentesco y nos basamos en nuestro trabajo de entrevistas con postulantes realizadas en el marco de una investigación más amplia. Sugerimos la noción de un punto de inflexión en sus representaciones, experimentado como el acontecer de un deseo impostergable de ser padres, el cual permite una transición entre la idea inicial de ser familia mediante la reproducción biológica y la decisión de adoptar.

Palabras Clave: parentesco, adopción, familia, filiación, biología, afectos

\begin{abstract}
In this article we tackle the difficulties, motivations and processes made by adoption applicants in Buenos Aires since their enrolement in what is generally known as the "legal circuit". We explore the concepts and reformulations that these men and women make about family, biological or social connections and adoption during the period within the beginning of their projects to become parents -often through biological procreation and the new reproductive technologies (NRT)- and their option for adoption, often facing up the conflicts suffered with medical treatments or due to involuntary infertility. We start from the theoretical perspective of kinship anthropology and we rely on our work of interviews with applicants in the context of a wider investigation. We suggest the notion of a turning point in their representations, experienced as the occurrence of an urgent desire to be parents, that allows a transition between the initial idea of being family through biological reproduction and the decision to adopt.
\end{abstract}

Key Words: kinship, adoption, family, biology, affection.

${ }^{1}$ Enviar correspondencia a: marielapena6@gmail.com 


\section{perifèria}

Número 20 (1), junio 2015

http://revistes.uab.cat/periferia

\section{Introducción}

En este artículo abordamos cuestiones relativas a los procesos, los sentidos y las prácticas concretas mediante las cuales se conforman las familias adoptivas en Argentina. Nos ocuparemos específicamente del análisis de las representaciones en torno al parentesco y la adopción por parte de quienes se inscriben y transitan un proceso de varios años, por lo general, antes de concretar una adopción.

Durante nuestro trabajo de campo hemos observado que en este período de tiempo que se asume como costoso, doloroso y sacrificado (Tarducci 2011), los postulantes a adopción frecuentemente se agrupan o asisten a talleres, reuniones y distintos espacios. Estas instancias -de acuerdo con sus palabras- cumplen esencialmente una función de "acompañamiento" en lo que se percibe como una evolución o "maduración" como madres y padres adoptivos (Autor y Tarducci 2012). Otros/as transitan esta etapa previa de forma más independiente, pero durante este recorrido suelen elaborar y objetivar sus sentimientos, preocupaciones y "ansiedades", así como sus nociones en torno a la maternidad, el parentesco y la adopción.

En esta ocasión, retomamos los avances ya desarrollados en la bibliografía experta (Modell 1994, 1998; Fonseca 2009, 2010) en torno al modelo de adopción, que al establecer un tipo de filiación que sustituye entera e irrevocablemente a la biológica, no propone un nuevo tipo de familia sino que intenta crear una imitación de la familia occidental formada a partir de la reproducción sexual y la pareja heterosexual. Contrastando dichas elaboraciones teóricas con nuestro trabajo de campo, proponemos que este marco normativo sobre la adopción y el parentesco actúa aún hoy, en nuestro ámbito de estudio, a modo de "prisma cultural" (Bestard Camps 2004). En otros términos, interviene como una forma o modelo específico para establecer relaciones, a través del cual se evalúa e intenta adecuar la construcción de familias mediante la adopción.

Aquí nos proponemos explorar las ideas y las valoraciones a través de las cuales los postulantes a adopción dialogan con este modelo en el contexto local. En función de esto, nos centramos en los sentidos que estas mujeres y varones construyen en torno al tránsito entre la intención de convertirse en madres y padres mediante la biología, muchas veces asistida por las nuevas tecnologías reproductivas (NTR), y la idea de la familia adoptiva. 


\section{perifèria}

Número 20 (1), junio 2015

http://revistes.uab.cat/periferia

Sugerimos la incidencia de un punto de inflexión vivenciado a modo de quiebre en los recorridos y motivaciones personales hacia la adopción, a partir del cual se sobrepone la idea de que "no hay vuelta atrás" y una sensibilidad del orden del afecto, experimentada como "dolor" profundo en relación con la imposibilidad de convertirse en madres y padres. A partir de estas percepciones frecuentemente se desestima por completo la relevancia de las conexiones biogenéticas o la intención de que el hijo sea propio a través de la sangre, enfatizando la importancia del deseo de formar una familia, el cual se impone como impostergable y como necesidad. Con el propósito de desarrollar estos argumentos, ahondamos en los modos en que las personas que comienzan a pensar en la adopción van modificando y construyendo significados sobre el parentesco de manera dinámica a lo largo del tiempo que transcurre entre las instancias iniciales y la decisión de adoptar- con un marcado carácter procesual, reflexivo y mutable (Carsten 2000, Franklin y Mc Kinnon 2001, Thompson 2001).

Por último, si bien damos cuenta de modificaciones graduales, tránsitos y tensiones entre viejos y nuevos sentidos, sostenemos la persistencia del modelo cultural tradicional de familia y filiación, y observamos que los cambios que están teniendo lugar -con sus reconocibles potencialidades- no implican hasta hoy su reconsideración sustancial.

\section{Consideraciones metodológicas}

Las trayectorias de las que damos cuenta han sido reconstruidas a partir de 50 entrevistas en profundidad realizadas a parejas heterosexuales de postulantes a adopción, que constituyen la mayoría numérica y a quienes hemos considerado como "norma" entre la totalidad de inscriptos legalmente en el Registro Único de Aspirantes a Guardas con Fines de Adopción (RUAGA) en Buenos Aires. Las entrevistas han sido realizadas en diferentes instancias de la investigación, entre los años 2010 y 2014, y las personas han sido contactadas a partir de redes personales o profesionales y del método de "bola de nieve". Además, hemos utilizado medios informáticos para difundir nuestro interés y el propio trabajo de campo como espacio para entablar nuevos contactos. Nos acotamos a familias residentes en la ciudad de Buenos Aires y Conurbano Bonaerense, que se han inscripto para adoptar durante la última década, quienes casi en la totalidad de los casos pertenecen a los sectores medios. En algunas ocasiones los encuentros han 


\section{perifèria}

Número 20 (1), junio 2015

http://revistes.uab.cat/periferia

sido con ambos miembros de la pareja, otras veces solamente con la mujer, y en algunas oportunidades pudimos realizar conversaciones de las dos maneras con las mismas personas. El número de entrevistas llevadas a cabo para cada categoría mediante esta modalidad de distribución se describe brevemente a continuación en la Tabla 1:

\section{Tabla 1}

Entrevistas realizadas distribuidas de acuerdo al género de los entrevistados y a la modalidad individual o en pareja.

\begin{tabular}{lllll}
\hline & Mujeres & Parejas & Ambas & Total \\
\hline $\begin{array}{l}\text { Cantidad de } \\
\text { entrevistas }\end{array}$ & 28 & 16 & 6 & 50 \\
\hline
\end{tabular}

\section{Notas:}

1. Hemos contabilizado a cada persona una sola vez, distinguido a aquellas mujeres a quienes entrevistamos de manera individual, de aquellos que acudieron en pareja y por último a aquellas que hemos entrevistado de ambos modos.

2. La decisión de entrevistar a ambos integrantes de la pareja de forma individualizada o conjunta ha sido negociada con los/as sujetos de estudio, estableciendo un límite inferior de 25 entrevistas a mujeres de manera individualizada en base a orientaciones teóricas y metodológicas de la investigación más amplia, de la cual este artículo se desprende.

3. La totalidad de los entrevistados pertenecen a sectores medios urbanos, quienes constituyen la amplia mayoría de familias adoptantes en la Argentina. Este tipo de circulación de niños y niñas desde hogares extremadamente humildes hacia las capas medias ya ha sido documentado en otros casos para el contexto de Argentina (Tarducci 2011).

\section{Las familias que se inscriben para adoptar, la biología primero}

Frecuentemente, las personas que deciden adoptar como "matrimonios" (un requisito legal vigente para adoptar en forma conjunta en Argentina es el estar casados) lo hacen debido a la imposibilidad de engendrar hijos a partir de la procreación biológica. En primer lugar suelen recurrir a tratamientos de reproducción asistida mediante el uso de las diferentes nuevas tecnologías reproductivas (NTR) y, una vez agotadas dichas posibilidades, comienzan con los trámites para adoptar. 


\section{perifèria}

Número 20 (1), junio 2015

http://revistes.uab.cat/periferia

Los relatos más recurrentes dan cuenta de un tiempo previo que puede durar varios años, en los cuales los intentos de fecundación, los estudios para encontrar las causas del problema y los tratamientos médicos son vividos con mucha angustia por ambos miembros de la pareja. En otros casos, han atravesado pérdidas reiteradas de embarazos por causas desconocidas, que resultaban muy dolorosas y frustrantes:

"En mi caso yo quedo embarazada pero lo pierdo, y el último fue el embarazo más largo que tuve, en cama, medicada. Lo que yo tengo es una trombosis en el cordón umbilical, y estuve un año hasta que me descubrieron qué tenía, después me hice tratamientos pero se me hizo trombosis coronaria también, la pasé muy mal, y dije basta, ese fue el último tratamiento que me hice, nunca más". (Entrevista a Karen, dos hijas adoptadas)².

"Fue muy complicado, después de una operación que tuve empezamos con esto, y bueno, vimos que no había noticias, no pasaba nada, hasta que me descubren las trompas obstruidas. Es algo genético, pero es que antes no se descubre, me hicieron un estudio horrible para ver si lo podían detectar, horrible. Creo que fue Dios que por algo quiso que sea, para fortalecerme. Después de todo esto, que me detectan que estaban, no atrofiadas, como acogotadas me explicaron, bueno, me opero, y tengo un paro cardiorespiratorio durante la operación [...]. Y después quedo embarazada dos veces, uno lo perdí, el otro me lo tuvieron que sacar porque era entrópico. Nos anotamos porque dijimos 'ya está', mi marido dijo: 'ya más no voy a arriesgar', fue así". (Entrevista a Ana, una hija adoptada).

Luego de varios intentos, la mayoría de las mujeres que hemos entrevistado han expresado que "no soportaban" o consideraban "agresivos", "invasivos" y "costosos" los tratamientos de fertilidad, tanto física como emocional, o económicamente:

"A los tres años de ver que no podíamos tener hijos empezamos los tratamientos, pero eran muy invasivos, y además las pérdidas de embarazo después de hacer un tratamiento son terribles, yo nunca lo presioné a mi marido para que adoptemos, después del último que hice vimos que no funcionaba, y los dos dijimos basta". (Entrevista A Silvina, un hijo adoptado).

\footnotetext{
${ }^{2}$ Los nombres de los y las entrevistadas han sido modificados para respetar su anonimato.
} 


\section{perifèria}

Número 20 (1), junio 2015

http://revistes.uab.cat/periferia

"Después empecé a hacerme tratamientos más serios digamos, con inyecciones, que además me provocaban otros síntomas [...]. Fue muy duro, en un momento empezó a ponerse cruento porque había estudios, el de las trompas por ejemplo, que me dejaron dos días en cama después". (Las cursivas son propias). (Entrevista a Viviana, dos hijas adoptadas).

Sin embargo, también hemos encontrado trayectorias alternativas, menos frecuentes, en las cuales el propósito de tener hijos se impone como deseo y se recurre de forma simultánea a más de una vía para llegar a ello, sin privilegiar la procreación biológica. Esta opción incluso desafía los consejos desde otros discursos de expertos y autoridades, de no realizar ambos procesos al mismo tiempo:

Mariana: "En 2001 dejamos de cuidarnos, pero fue un proceso de un año y medio anterior, de empezar a tener la idea. Después pasaban los meses y no pasaba nada, y decidimos consultar, ahí creo que empezó a pesar el tema de la edad, yo tenía 35, empezamos a hacer estudios en paralelo, y rápidamente descubrieron que él tenía varicocele. Pero al mismo tiempo comenzamos los trámites para adoptar, que siempre te dicen que no lo hagas, pero a nosotros no nos importó. Después él se operó, tuvo un tiempo de recuperación, seguimos viendo que no pasaba nada, y determinaron que esa era la causa. Hicimos unos tratamientos...tecnológicos...estimulación ovárica, y dijimos: 'hasta acá llegamos'. Al mismo tiempo, era 2003, nos habíamos anotado en varios registros, porque todavía no existía el Registro Único. Entonces averiguamos en los distintos organismos que armaban la carpetas, primero fuimos a [nombre] pero no nos gustó, y después nos quedamos con el San José, porque nos parecía más adecuado". (Las cursivas son propias).

Antropóloga: "¿Para vos cómo fue ese momento en el que descartaron los tratamientos, hubo un tiempo entre esto y la idea de continuar con las adopciones?".

M: "No, para mí no, lo que sí te puedo decir es que fue doloroso, triste, después de haber hecho un tratamiento, que no funcione. Pero no fue más que eso".

A: "¿Tenías muy presente el tema del embarazo?".

M: "Sí, tenía ganas, incluso estaba conversado y fantaseado, el tema de la panza, elegir el nombre. Pero te puedo decir que no me gustaba ir a la clínica, 


\section{perifèria}

Número 20 (1), junio 2015

http://revistes.uab.cat/periferia

no me parecía tan importante hacer todo eso para que sea biológico, no era lo que había imaginado". (Entrevista a Mariana, un hijo adoptado).

$\mathrm{Y}$ en algunas entrevistas, los problemas de fertilidad se han combinado o han sido resultado de la decisión de postergar la maternidad y paternidad:

"Nosotros cuando nos fuimos a convivir, yo tenía 38 años, y nuestra situación económica en ese momento no era buena, tuvimos un problema con el crédito para comprar la casa, y estuvimos unos años viviendo en la casa de la mamá de él. Por eso cuando buscamos y veíamos que no pasaba nada empezamos los estudios, y como yo tenía más de cuarenta mi útero estaba deformado, el endometrio no tenía el espesor que necesitaba, y él tampoco tenía buenos niveles de esperma [...]. Tomamos una medicación para aumentar la fertilidad, pero nos quedamos en los estudios, no hicimos otros tratamientos porque las chances ya eran muy pocas". (Entrevista a Marta y Lorenzo, sin hijos).

"Durante unos años decidimos no tener hijos, yo no me veía como madre, los dos estudiábamos y trabajábamos, no me veía con un bebé, y él estuvo de acuerdo". (Entrevista a Marina, un hijo adoptado).

"Al principio teníamos a mi suegro con nosotros, no queríamos saber nada, después terminamos con ese tema y queríamos disfrutar un poco nosotros, empezamos a salir, y después a mí me descubrieron el virus HPB y estuve unos años tratando eso, así que hasta los 34 años fue imposible, recién ahí empezamos a probar". (Entrevista a Ana).

Muchas veces la posibilidad de adoptar está conversada en la pareja como una opción, aunque lejana, incluso antes del momento de planear la llegada de los hijos. Frente a esta situación más concreta de dificultades con los tratamientos médicos, algunos retoman la idea como algo "que estaba ahí desde siempre":

Oscar: "Cuando empezamos a salir, hablando en general, para conocernos, ella me pregunta: 'y si por algún motivo no pudieras tener hijos, ¿adoptarías?', y yo le dije que sí, no tenía ningún problema. Eso había sido como diez años antes, así que cuando nos cansamos de los tratamientos decidimos adoptar". (Entrevista a Viviana y Oscar). 


\section{perifèria}

Número 20 (1), junio 2015

http://revistes.uab.cat/periferia

"Ya desde novios, dijimos: '¿y si no podemos tener hijos qué?', 'Y...adoptaremos'. Una salida natural. No fue planeado, pero viste cuando decís: 'cuando nos casemos pintaría el living de verde', 'no, me gusta amarillo', 'bueno, lo pintamos de amarillo', cada uno sabía la posición del otro. Igual fue fuerte cuando yo fui a buscar los resultados, ese momento...porque una cosa es proyectar la familia, y otra cosa es enfrentarte con la realidad de que la vas a tener que buscar seriamente. No es cuestión solamente de decidir que no nos cuidemos, había que buscar los métodos, y la verdad lo encaramos, no con mucho ahínco, esto de los tratamientos". (Entrevista a Mabel y Germán, 3 hijos adoptados).

En ocasiones, parejas que han pasado años realizando tratamientos que no han dado resultado, restan importancia a las diferencias entre la procreación biológica y la adopción, pero quienes han expresado esto se sienten diferenciados de "la mayoría":

"Ya cuando hablábamos de tener hijos, en general siempre teníamos un concepto más amplio que el resto, no tenían que ser biológicos, hablábamos de que la adopción nos parecía una experiencia interesante, y también una oportunidad a chicos que no tenían la posibilidad de vivir en una familia". (Entrevista a Claudia, un hijo adoptado).

Estela: "Nuestro caso fue especial porque ya de novios dijimos, vamos a adoptar un chico, aun teniendo los nuestros, o sea que....intentamos al año de casados, no pudimos, nos hicimos ochenta mil cosas, yo me hice, pero siempre apuntando a cuando iba a ser el tiempo de que la ley permitiera...lo de los tres años de matrimonio."

Antropóloga: "¿La decisión de dejar los tratamientos cómo fue?"

$\mathrm{E}$ : "Porque eran invasivos totalmente, te entregás a que te hagan lo que venga a cualquier costo." (Entrevista a Estela, dos hijos adoptados).

Usualmente, la decisión de adoptar y los primeros pasos en esa dirección suceden a los tratamientos con NTR e intentos de embarazo sin grandes intervalos de tiempo, o tal vez de forma inmediata -lo cual desde las perspectivas psi suele considerarse poco propicio para realizar un "duelo" de manera correcta (Pena 2013)³. Esta

${ }^{3}$ En trabajos previos hemos analizado la presencia y la autoridad de los discursos de las disciplinas psi en el campo de las adopciones, mediante la descripción de valoraciones impartidas por profesionales del 


\section{perifèria}

Número 20 (1), junio 2015

http://revistes.uab.cat/periferia

situación suele ser acordada entre la pareja, muchas veces siendo uno de los dos él o la que "insiste" o presenta menos dudas. Como vimos, algunas parejas incluso deciden ponerle fin a las intervenciones médicas antes de agotar las posibilidades, debido a sus costos o consecuencias. Otros, a la vez, consideran la adopción como preferible frente a algunas prácticas "demasiado artificiales" o que creen alejadas de la reproducción natural:

"En un momento charlamos la posibilidad de probar con un banco de esperma, pero no, a mí eso de que me pongan esperma de otro hombre me daba asco, soy antigua, eso siempre lo tuve claro. Para mí un hijo es fruto del amor, nace de dos personas que se aman, no me gusta eso otro, no, no. Si no existiera la adopción hubiera preferido no tener". (Entrevista a Marta y Lorenzo).

"Cuando hacés el tratamiento de fertilización, vos vas con tu marido, con tu pareja, estás acostada en una camilla, y cuando termina, los médicos te dejan solos. Entonces nos dejaron, pusieron una luz tenue, para que estemos un rato juntos, y nos pasó a los dos, en vez de sentir intimidad, no lo pudimos sentir así, creo que le pasa a cualquier persona, porque no es así. Es algo inexplicable, y muy personal, esa cosa así muy fría, no lo pudimos sentir como algo para nosotros". (Entrevista a Ana).

Lo que nos interesa destacar aquí se vincula con la expresión recurrente en muchas mujeres y parejas de que en ese momento (cuando decidieron la opción de adoptar) se les ha impuesto de manera más evidente su deseo de "convertirse en madres", de alguna forma, sobre el anhelo de "tener un hijo" que sea propio por el hecho de compartir la biogenética y el parto. En este sentido, como desarrollaremos a continuación, creemos que para dar cuenta de la afectividad y de las nociones que guían las prácticas de las futuras familias adoptivas, ellas deben reconstruirse desde una perspectiva procesual (Thompson 2001) atendiendo a su carácter maleable, contradictorio y dinámico.

área que ocupan posiciones clave en diferentes instituciones -públicas o privadas- destinadas principalmente a postulantes y a familias adoptivas (Pena 2013). 


\section{perifèria}

Número 20 (1), junio 2015

http://revistes.uab.cat/periferia

\section{El acontecer de un quiebre o "ya no hay vuelta atrás"}

En este punto nos interesa traer a colación las elaboraciones desarrolladas por Howell (2001, 2003, 2009) durante su estudio con familias adoptivas europeas. Esta autora ha argumentado que entre las madres y padres adoptivos, a diferencia de las representaciones sociales dominantes, opera un "modelo dinámico" (Howell 2003: 467) de parentesco que en diferentes momentos o contextos, privilegia uno de ambos aspectos (biología/sociabilidad) sobre el otro. Aquellas contradicciones que desde una mirada externa aparecen como irreconciliables, son resueltas con relativa facilidad por parte de las familias adoptivas.

En relación con esto, a partir de las observaciones que se desprenden de nuestro trabajo de campo, nos interesa puntualizar en ciertas especificidades del contexto estudiado y profundizar en la idea de que en determinada instancia de las trayectorias suele ocurrir el advenimiento de un "punto de inflexión", a partir del cual se decide optar la adopción privilegiando el deseo de convertirse en familias. A partir de aquí, las distancias con el plan inicial (basado en la reproducción biogenética) son apartadas o soslayadas. En función de ello, el propósito de adoptar se emprende con una alta cuota de entusiasmo y compromiso, y no suele ser interrumpido o desechado fácilmente.

Como una de las manifestaciones principales de dicho nuevo modo de percibir el proyecto para convertirse en familias, hemos observado en nuestro caso que algunas mujeres y parejas elaboran, a posteriori de la etapa de tratamientos, la idea de que el privilegio por la descendencia biológica forma parte de un "mandato social" y/o familiar:

Rosana: "Está el chiché social de que tenés que tener un hijo biológico, parecido a vos, como un mandato, yo lo sentía, en el caso de mi mamá por ejemplo, había una presión, pero nos parecía más importante no sacrificar la pareja"

Gerardo: "En mi familia estaba el tema de que yo soy el único varón, y el último que lleva el apellido, entonces lo biológico estaba como importante, voy a defraudar a mi familia". (Entrevista a Rosana y Gerardo, sin hijos).

Mabel: "Cuando empezamos con los tratamientos, que son crueles, (y hace diez años eran más crueles todavía), un día nos preguntamos los dos si 


\section{perifèria}

Número 20 (1), junio 2015

http://revistes.uab.cat/periferia

queríamos tener hijos biológicos o queríamos tener hijos, y bueno, este duelo, que no nos costó nada el duelo, de verdad te decimos..."

Antropóloga: "¿Pueden contarme más sobre eso del duelo?"

M: "Por lo que escuchamos, porque nosotros tenemos además muchos amigos, a ellos les costó asumir la no paternidad biológica. Pero nosotros, si hubiéramos tenido algún problema, te lo contaría. El único problema hubiera sido con la mamá de él, el mandato, que había que tener un hijo biológico, con las mismas características, que iba a ser altísimo como nosotros, es decir, lo genético.". (Entrevista a Mabel y Germán).

A diferencia del contexto explorado por Howell, que ha encontrado entre las familias adoptivas que estudió una motivación ligada a las presiones de la vida social adulta y al deseo de "convertirse en familias normales" para no sentirse excluidos (Howell 2003: 469), en nuestro campo la interacción con otros pares no se ha manifestado como un aspecto tan significativo. La maternidad y paternidad se han presentado más como deseos de realización personal que como un modo de integración en los espacios de sociabilidad. Una coincidencia importante que sí hallamos con esta otra etnografía tiene que ver con el cambio notable en las actitudes respecto a que sus hijos puedan ser gestados biológicamente por otros cuerpos. Aquellos aspectos que inicialmente habían sido privilegiados como vías de conformación familiar, sometiéndose a tratamientos costosos como los que señalamos antes, luego son desdeñados. En palabras de una de las mujeres entrevistadas:

"Si a mí me firman que yo voy a ser mamá, que me van a dar una adopción, ni hubiera empezado con los tratamientos, a esta altura ni loca vuelvo a pasar por eso, me parece que la maternidad pasa completamente por otro lado, es algo que ya tengo claro". (Entrevista a Josefina)

De este modo, consideramos que en este momento de las trayectorias que analizamos, deja de ser prioritaria la forma en que se conformará la nueva familia y se presenta la idea de convertirse en madre o padre como un deseo impostergable. A pesar de esto, no pretendemos sugerir la idea de un cambio íntegro sin lugar para vacilaciones o contradicciones. Por el contrario, los ideales y los modos de pensar el parentesco, en especial la relevancia de los lazos se sangre como símbolo de las conexiones familiares, retornan o se muestran de maneras diversas. A modo 


\section{perifèria}

Número 20 (1), junio 2015

http://revistes.uab.cat/periferia

de ilustración de este punto, cuando indagamos en torno a las cuestiones por las cuales la adopción no había sido considerada anteriormente, y en relación con los asuntos que aún en ese momento les planteaban dudas y preocupaciones, nos hemos encontrado en especial con una preocupación recurrente. Se refería al temor, manifestado de diferentes formas, a que el amor o afecto entre los padres y el hijo o hija adoptiva sea más débil, "no aparezca" o sea "más difícil de construir":

"Bueno, el tema de que sea bebé tenía que ver con los temores... Más que nada tenía esa incertidumbre de cómo iba a ser, cuando nos conociéramos, cómo iba a reaccionar, él y yo". (Entrevista a Fernanda, un hijo adoptado).

Lorenzo: "Y yo pensaba, que sé yo si lo que me daban me iba a gustar, si en el momento del encuentro lo iba a querer. A ver, el ser padre es una costumbre, uno lo hace convencido, no es solamente una cuestión de la naturaleza, pero para que te salga ese sentimiento de ser padre tienen que darse una serie de cosas. Yo no sé si me traen un nene y lo voy a ver y lo voy a querer".

Marta: "Pero eso es con el tiempo, con el día a día, con el hijo biológico también te puede pasar".

L: "Sí, sí, pero no sé...quizás son los mandatos".

Antropóloga: "¿Creés en algo que surge más espontáneamente si es biológico, por ejemplo?"

L: "Sí, hay un componente, biológicamente hay algo creo". (Entrevista a Marta y Lorenzo).

"Para mí el principal desafío frente a la adopción era saber si los ibas a poder querer como hijos, y esa es la mayor alegría, saber que sí, sí podés, ahora sobre mi cadáver me vas a decir que no son mis hijos". (Entrevista a Lidia, dos hijos adoptados).

"Ahora me estás haciendo acordar, mi miedo era si la voy a querer o me va a querer, al principio, tenía temor de que ella me rechace [...]. No sé cómo será tener una hija...propia, digamos, de tu propia sangre, que estás nueve meses con ella. En este caso hubo un año y cuatro meses que no estuvo conmigo, y de golpe...hubo veces que veía como que tenía como un poquito de desconfianza, que se apartaba, no miedo ni nada, porque no tenía reflejo de defenderse [...]. Ah, y una vez ella empezó a llorar a la noche, la voy a 


\section{perifèria}

Número 20 (1), junio 2015

http://revistes.uab.cat/periferia

buscar, y decía: 'mamá, mamá', y yo le preguntaba: '¿Qué?', y me dice: 'No, no, mamá, mamá'. No sabés como me largo a llorar y le digo a mi marido: 'No me quiere a mí, quiere a la mamá', y él me dice: 'iSos vos la madre!'." (Entrevista a Gabriela).

Este sentimiento ha sido manifestado tanto por mujeres como varones, pero suele considerarse (muchas veces con ayuda del discurso psi) una "fantasía" infundada que podrá superarse. Para las parejas que conocimos no ha constituido un motivo para descartar la adopción una vez que los tratamientos han fracasado o han causado demasiados inconvenientes. En esta instancia, luego de varios años de intentos sin los resultados esperados, la posibilidad de adoptar se presenta como una oportunidad deseada, un recurso esperanzador y un proyecto que se encara con mucha energía y voluntad. En casi la totalidad de los casos que contactamos constituye el anhelo y objetivo principal de estas parejas, que no suelen mostrarse titubeantes una vez que inician los trámites, sino muy decididas. $Y$ aquí retornamos al concepto de punto quiebre o inflexión, lo cual genera la percepción -de acuerdo con la expresión reiterada por muchas/os de los entrevistados- que "ya no hay vuelta atrás".

Otra variante que colabora con la noción que proponemos -en relación con la imposición de un giro o desplazamiento a partir del cual son desestimados los aspectos biológicos- consiste en que los parecidos físicos también se presentan, a esta altura de las trayectorias, como cuestiones irrelevantes y también moralmente negativas. Los postulantes a adopción o quienes ya han adoptado (siguiendo los procedimientos burocráticos legítimos) se han esforzado por dejar claro que incluso las diferencias fenotípicas son cuestiones que no les atañen ni deberían hacerlo, o que toman con humor:

"En las entrevistas [del RUAGA] me preguntaron si tenía algún problema con las diferencias físicas [hace un gesto de indignación]. Yo te digo, mi deseo profundo, es que me vengan dos collas ${ }^{4}$ ahora, de verdad lo deseo, bien negros, con el pelo parado, me muero de amor. $Y$ si alguien los discrimina, se las va a tener que ver conmigo primero". (Entrevista a Rita, sin hijos).

"Yo creo que hay algunos matrimonios que aceptan [las diferencias fenotípicas] por descarte, y eso no es bueno digamos, el matrimonio que

\footnotetext{
${ }^{4}$ Grupo étnico presente mayoritariamente en regiones del Noroeste de Argentina.
} 


\section{perifèria}

Número 20 (1), junio 2015

http://revistes.uab.cat/periferia

agarra lo que hay porque 'ya hace 20 años que estamos esperando y estamos podridos', eso no es lo más deseable, pero sí creo que hay otros que tienen flexibilidad." (Entrevista a Estela, sin hijos).

Mabel: "Jamás nos preocupamos por eso, sólo porque lo sufran ellos afuera. Creo que ellos en algún lugar tienen esa carga de que físicamente no se parecen en nada, pero por el colegio, por nosotros no, el tema es que los dos....F es un poco más verdoso, E es más morocho..."

Germán: "iSon los dos negros! [Risas de los dos]"

Mabel: "Si queríamos ocultarlo, en el barrio iba a salir algo de: 'mmmm...algo no cierra...'" [Risas]. (Entrevista a Mabel y Germán).

Sugerimos que una vez ocurrida esta nueva orientación en el diseño de familia, en la que la adopción está ya decidida, la principal preocupación que reemplaza a la anterior es la incertidumbre de que finalmente pueda concretarse:

"A veces nos 'bajoneábamos' o no estábamos tan entusiasmados con lo de la adopción, porque te dan tantas vueltas...que los papeles, que la entrevista con la psicóloga...una vez nos rechazaron porque 'no habíamos hecho el duelo', nos mandaron a terapia, fuimos medio año, nos hicieron más entrevistas...así hasta que nos aceptaron. Habían pasado casi dos años y veíamos que se ponía cada vez más difícil". (Entrevista a Marta y Lorenzo).

"Yo nunca le tuve miedo a la adopción, a lo que sí le tenía miedo era a los trámites". (Entrevista a Silvina).

Y en relación con esto el acento de sus preocupaciones suele direccionarse ahora hacia el temor en torno a la salud del posible hijo/a adoptivo/a. En algunas entrevistas ha estado presente la idea de que la mayoría de los niños y niñas en adopción sufren problemas médicos graves y que las autoridades encargadas "no cuentan" toda la información:

"El único miedo era que...a ver...yo te conté que hubo dos intentos de adopción fallidos, y otro falleció en el momento en que lo buscábamos, entonces, después el único miedo era ese, que no llegues a poder tener un hijo o que el hijo...porque con la problemática de nuestro hijo en su momento el asesor de menores que correspondía a ese juzgado lo ocultó...ahora 


\section{perifèria}

Número 20 (1), junio 2015

http://revistes.uab.cat/periferia

supuestamente no se puede, pero te mienten con la edad, con la problemática. (Entrevista a Susana, un hijo adoptado).

Así, el lugar asignado a las conexiones biológicas, de acuerdo a lo que las observaciones nos permiten sostener, en este momento es relegado a un lugar secundario, manifestando que está "asumido" o "procesado", y se sopesa con los inconvenientes que les ha ocasionado la reproducción asistida y con la posibilidad de no tener hijos:

"Yo [cuando decidimos adoptar] lo que quería era tener un bebé en mis brazos, no me importaba si era adoptado, y como de chica me habían dicho que me iba a costar quedar embarazada, eso mi marido lo sabía y me había dicho que no le importaba, que prefería estar conmigo. Él en un momento ya no soportaba verme sufrir con los tratamientos, le dolía muchísimo, así que estaba todo bastante procesado ya". (Entrevista a Karen).

Beatriz: "A mí la experiencia de adoptar me costó más que a él, yo justo trabajaba con embarazadas y bebés y me costó mucho eso, con los bebés no porque sabía que no eran hijos míos, pero cuando veía las panzas, pensar que yo no podía hacer lo mismo era difícil. Pero bueno, me di cuenta de que lo que quería era ser madre, no estar embarazada."

Antropóloga: "¿Fue algo gradual?"

B: "Yo lo sentí más como un quiebre, un día dije, yo quiero tener un hijo, no me importa si no estoy embarazada. Pero en mi caso me llevó un tiempo".

Pablo: "Es que en un momento decís, ya está, si te quedás en esa idea de la gestación, no formás una familia, en un momento tenés que decidir, o sí o no". (Entrevista a Beatriz y Pablo, dos hijos adoptados). (Las cursivas son propias).

Ya no parece importar que el hijo o hija llegue mediante la adopción, sino que este anhelo que se vive de manera muy intensa y como un dolor profundo se pueda realizar. Dichas circunstancias generan, por otro lado, el hecho de que la maternidad y paternidad adoptiva se piensen y sean valoradas como parte de una meta y de un deseo "verdadero", sostenido en el tiempo y muy afianzado, a diferencia de la procreación biológica que puede suceder más espontáneamente o no implica tanto sacrificio y preparación: 


\title{
perifèria
}

Número 20 (1), junio 2015

http://revistes.uab.cat/periferia

\begin{abstract}
"Yo creo que entre la maternidad biológica y la adoptiva hay miles de diferencias, una cosa es que te pase de accidente y otra cosa es ser consciente de lo que estás haciendo, la madre adoptiva lo piensa, lo repiensa y es un proceso muy elaborado. Vos querés, vos deseás, vos luchás para hacerlo, sabés que tenés todo en contra, que te va a llevar quizás 10 o 15 años que te llamen, y al mismo tiempo ir olvidándote del tema, porque no sabés si te va a pasar". (Entrevista a Karen). (Las cursivas son propias).
\end{abstract}

\section{Algunas persistencias en el ideal de familia}

Las percepciones que hemos venido analizado se relacionan asimismo con el hecho de que a estas alturas, sino antes, las parejas toman conocimiento a través de contactos con otras personas, asociaciones o instituciones públicas, de que el tiempo que transcurre entre que se inscriben en el Registro Único y que la adopción se concreta puede ser de varios años, sin garantías de que llegue a realizarse. En la mayoría de los casos con los que hemos trabajado, y debido al contexto burocrático-legal actual en nuestro país (Pena 2014), los postulantes conocen que las etapas previas tienen una fuerte intervención estatal, a través de los organismos administrativos y judiciales correspondientes. Como hemos descrito en artículos previos, estos dispositivos se ocupan en primera medida de intentar "fortalecer el vínculo" con las familias de origen y consideran la adopción como un "último recurso". Las transferencias más informales de niños y niñas a partir de la decisión de mujeres de dar a sus hijos en adopción recurriendo a "intermediarios"conocidas localmente como "adopciones directas" ${ }^{5}$ - y documentada en otros casos (Fonseca 1998), también es muy frecuente en nuestro país (Tarducci 2011, 2012). Sin embargo, quienes se postulan actualmente saben que desde los últimos años han sido moralmente condenadas y manifiestan su acuerdo o ciertas reticencias ${ }^{6}$ :

"No digo que todas las entregas directas sean malas, lo que digo es que provoca una situación de mucho conflicto en general, y además no estoy

\footnotetext{
${ }^{5}$ El término hace referencia a adopciones realizadas mediante acuerdos de transferencias de niños entre particulares, que posteriormente son ratificados y legalizados a través de una autoridad judicial.

${ }^{6}$ En este punto vale la pena aclarar que algunas personas que entrevistamos se inscribieron hace alrededor de una década. Sin embargo, creemos los sentidos desde los cuales interpretan y cuentan su experiencia hoy están atravesados por los sentidos y valores actuales.
} 


\section{perifèria}

Número 20 (1), junio 2015

http://revistes.uab.cat/periferia

cuidando al chico, porque yo tengo la $\operatorname{carpeta}^{7}$ y me la aprobaron... pero ¿y si yo soy una loca, y me dan el chico, y soy una loca? Pensemos en la criatura...vivimos en un marco legal, es así, a la larga o a la corta todo lo que no es legal se corta, andá a la vida y todo después te trae un problema". (Entrevista a Graciela, sin hijos).

"El tema es que hay un artículo del Código Civil que dice que los padres pueden dar a su hijo en adopción, y en realidad no hay ningún artículo que prohíba que pueden elegir a los padres, no está legislado digamos, es una laguna del derecho. Entonces en base a eso, algunos jueces interpretan que la adopción directa es una forma de adopción. Mi punto de vista es que habría que confiar en que los jueces que se encargan de las adopciones directas sean honestos y hagan las cosas bien, legislarlo mejor, porque si lo prohibís del todo porque algunos lucran con eso, no le das la posibilidad a los que lo hacen con buenas intenciones". (Entrevista a Silvina).

Como contracara, también formando parte de la misma lógica que venimos analizando en nuestra investigación (Pena 2014) las adopciones realizadas desde el "camino legal" son pensadas como garantía de "haber hecho las cosas bien". Por lo tanto, la tradicional idea de ruptura con la familia de origen no tiene razones para ser cuestionada, sino que se presenta naturalizada y autorizada por el Estado.

De acuerdo con nuestro trabajo de campo, la importancia de las conexiones biológicas también puede ser ahora minimizada porque no importa cómo llega, será de igual forma un hijo o hija de la nueva familia.

Asimismo, creemos que a partir de estas representaciones se asignan determinados sentidos a la relación del niño con su familia de origen, frecuentemente relegada. El conjunto total de las personas entrevistadas acordaron en la relevancia y naturalidad de transmitirles a sus hijos la verdad de que son adoptados y que son, como todos los niños y niñas, nacidos biológicamente del vientre de una mujer. A pesar de esto, respecto a lo que suelen denominar como "historia" o "pasado" del hijo adoptivo, las respuestas no han sido uniformes.

Por ejemplo, ha sido reiterada -y conocida entre quienes están cerca de la problemática de la adopción- la idea de "no querer saber" algunas cuestiones para no "tener que contar" aspectos que podrían resultar dolorosos para los niños:

${ }^{7}$ Designación local para el conjunto de informes exigidos a postulantes a adopción por el Registro Único Nacional y por los diferentes registros judiciales de las provincias no adheridas. 


\section{perifèria}

Número 20 (1), junio 2015

http://revistes.uab.cat/periferia

"El tema más conflictivo es el de contar la verdad. Tanto mi marido como yo estábamos dispuestos a decir siempre la verdad, a él, a la familia, a todos, entonces si hay algo muy difícil, muy doloroso, pensaba, si yo no lo conozco, no lo puedo contar, no miento. Yo prefería no saber, al contrario de mi marido que no tenía problema. Pero hablo de algo muy puntual, muy doloroso, no de la historia en general". (Las cursivas son propias). (Entrevista a Marina, un hijo adoptado).

Pero para otras personas, este pasado "no era importante":

"De lo que pasó antes no te podés hacer cargo, el tema es hacer lo mejor posible a partir de que es tu hijo, por eso no sé si me interesa demasiado que me cuenten todo". (Entrevista a Nora, sin hijos).

Y para otras mujeres y varones, la importancia de conocer esta historia estaba muy presente. Se visualiza la relevancia de la información en torno a la identidad biológica como algo que puede requerirse en el futuro:

"En algún momento van a querer saber su historia, o conocer a su familia biológica, eso es así, es algo humano, los hijos biológicos también preguntan de dónde venimos, todos queremos saber nuestro origen, armar nuestra identidad. Como madre espero poder estar ahí y acompañarlos cuando sea el momento, que sepan que estoy". (Entrevista a Verónica, sin hijos).

Sin embargo, todas estas variantes coinciden en la ausencia de un planteo en torno a la posible continuidad de estos lazos familiares de origen. Dada la relevancia que consideramos tiene este aspecto, nos interesa reparar en el hecho de que a pesar de que se minimiza la importancia de las conexiones biológicas, la intención de semejanza con la familia de filiación exclusiva no resulta por lo general modificada en lo esencial. La adopción continúa pensándose como un nuevo comienzo (Modell 1994) y prevalece la idea de que el hijo o hija adoptada a partir de ese momento es propio y pertenece solamente a la nueva familia.

También creemos que permite dar cuenta de estos sentidos la prioridad que tienen los bebés y niños pequeños en el "ofrecimiento" que hacen los postulantes cuando se inscriben, pese a que el rango de edad se ha visto ampliado respecto a años anteriores debido a la "escases" de bebés en situación de adoptabilidad. Varias cuestiones aparecen estrechamente ligadas en concepciones que relacionan la corta 


\section{perifèria}

Número 20 (1), junio 2015

http://revistes.uab.cat/periferia

edad de los niños o niñas con mejores posibilidades de "construir un buen vínculo" y con temores o dificultades para adoptar niños o niñas más grandes:

"Cuanto más chiquitito, más preservado. Yo estaba estudiando estimulación temprana, justo, y eso era algo que estaba presente". (Entrevista a Marina).

"En el primer ofrecimiento pedimos un niño o niña de hasta un año, fue algo que hicimos con total entusiasmo, eso fue durante todo el primer año, todas las semanas llamábamos a los juzgados de las provincias, para estar presentes, y nos llamaron a los 20 meses, eso fue con nuestra primera hija, y fue fantástico. Para la segunda sabíamos que estaba difícil y aceptamos ampliar la edad, nos animamos pero pensando que iba a ser diferente". (Entrevista a Viviana y Oscar).

En otras ocasiones el privilegio por un bebé o un niño pequeño se presenta como un deseo cuyas motivaciones resultan difíciles de explicar:

"No sé, la verdad es que quería tener la experiencia de criar un niño desde chiquitito". (Entrevista a Clara, una hija adoptada).

Y sumado a esto, como mencionamos anteriormente, ocupa un lugar muy importante el temor a que el amor hacia los hijos adoptados, y de ellos a su madre y padre, no aparezca o tarde en aparecer, o la idea de que cuanto más grandes sean, será más difícil:

"Cuando son chiquitos se da más fácil [el afecto entre madre e hijo], sí, porque vas creciendo con ellos". (Entrevista a Gabriela, una hija adoptada).

Tomando en consideración estos relatos y valoraciones, como adelantamos en la introducción, es posible sugerir que el anhelo de la mayoría de los postulantes es construido a partir del modelo de familia al que hemos referido, el cual opera a modo de prisma cultural (Bestard Camps, 2004) en relación con el parentesco y prescribe como ideal normativo la semejanza con la familia natural.

\section{Conclusiones}

Las concepciones que dan forma y contribuyen a crear parentesco en las familias adoptivas son construidas y negociadas durante un tiempo que excede y se anticipa a la llegada de un niño o niña en adopción. Estos sentidos van cobrando forma de diversos modos y mediante interacciones con distintos tipos de actores: familias 


\section{perifèria}

Número 20 (1), junio 2015

http://revistes.uab.cat/periferia

que ya han adoptado, expertos en adopción, asociaciones dedicadas al tema, organismos estatales, entre otros, que se entrelazan con procesos y elaboraciones subjetivas. Todos estos factores colaboran y se disputan la producción de sentidos que normativizan una cierta forma de pensar y actuar las adopciones, aunque con lugar para la variabilidad y algunas contradicciones.

Por eso, en este trabajo elegimos abordar la construcción de representaciones por parte de quienes se postulan para adoptar, considerando que frecuentemente transcurre un lapso de tiempo durante el cual se desarrollan estas elaboraciones.

Nos dedicamos a describir e interpretar las motivaciones y trayectos de los "matrimonios" que se inscriben para adoptar y siguen "el camino legal". Dimos cuenta de los tránsitos y las resignificaciones dinámicas y procesuales realizadas entre los inicios de un proyecto que por lo general comienza priorizando la reproducción biológica, y luego, sugerimos, desplaza la importancia de estas conexiones enfatizando en el deseo de convertirse en madres y padres. Complementamos las reflexiones elaboradas en otros contextos etnográficos en torno al "modelo dinámico" sobre el parentesco que opera entre las familias adoptivas (Howell 2003) mediante su comparación con la coyuntura Argentina. Asimismo, agregamos la noción de un punto de inflexión o quiebre en las nociones y también en los afectos de los postulantes, el cual les permite realizar el tránsito entre la idea inicial de convertirse en familias mediante la reproducción biológica y la adopción, y pensar en esta última como una forma de crear conexiones tan deseada y legítima como la procreación y/o la asistencia de las nuevas tecnologías reproductivas.

Por último, intentamos mostrar que desde los discursos que trabajamos no se replantea el modelo de adopción descripto por Modell (1994) hace ya varios años, y que a pesar del reconocimiento de la historia, la verdad y los orígenes, continúa prevaleciendo la idea de pertenencia exclusiva a una familia. Sostenemos que las reflexiones de este artículo permiten pensar en un ideal o modelo respecto al parentesco (trasladado a la práctica de la adopción) actuando hoy en nuestro contexto local como prisma cultural, orientando el punto de vista sobre los aspectos que para quienes desean adoptar se presentan como problemáticas. La concepción de que los niños y niñas, a partir de que son pensados como hijos, pertenecen de manera exclusiva a una familia, sugerimos, no ha sido cuestionada o modificada en lo esencial. 


\section{perifèria}

Número 20 (1), junio 2015

http://revistes.uab.cat/periferia

\section{Bibliografía}

Bestard Camps, Joan (2004). "Kinship and the new genetics. The changing meaning of biogenetic substance". Social Anthropology, vol. 12, 3, pp. 253-263. DOI: $10.1111 / \mathrm{j} .1469-8676.2004 . t b 00107 . x$

Carsten, Janet (2000). "Introduction: cultures of relatedness". En: Carsten, Janet (ed.) Cultures of Relatedness: New approaches to the study of kinship. Cambridge: Cambridge University Press, pp. 1-36.

Fonseca, Claudia (2010). "Del 'tráfico de niños' a las adopciones necesarias. La evolución reciente de políticas de adopción en Brasil". En: Villalta, Carla (comp.). Infancia, justicia y derechos humanos. Buenos Aires: Universidad de Quilmes, pp. 109-134.

(2009). "Transnational connections and dissenting views: the evolution of child placement policies in Brazil". En: Marre, Diana y Laura Briggs (comps.). International Adoption. Global inequalities and the circulation of children. New York: New York University Press, pp. 154- 173.

(1998). Caminos de Adopción. Buenos Aires: Eudeba.

Franklin, Sarah y Susan Mc Kinnon (2001). "Introduction". En: Franklin, Sarah y Susan Mc Kinnon (eds.) Relative Values: Reconfiguring Kinship Studies. London: Duke University Press, pp. 1-28.

Howell, Signe (2009). "Adoption of the unrelated child: Some challenges to the Antropological Study of Kinship". En: Annual Review of Anthropology. DOI: 10.1146/annurev.anthro.37.081407.085115 (2003). "Kinning: The creation of the life trajectories in trasnational adoptive families". Journal of the Royal Athropology Institute, vol 9, pp. 465-484. DOI: $10.1111 / 1467-9655.00159$

(2001). "Self-Conscious Kinship: Some contested Values in Norwegian Transnational Adoption". En: Franklin, Sarah y Susan Mc Kinnon (eds.). Relative Values: Reconfiguring Kinship Studies, pp. 175-202.

Modell, Judith (1998). "Rights to the children: foster care and social reproduction in Hawai". En: Franklin, Sarah y Helena Ragoné (eds.). Reproducing reproduction: 


\section{perifèria}

Número 20 (1), junio 2015

http://revistes.uab.cat/periferia

Kinship, power and technological innovation. Pennsylvania: University of Pennsylvania Press, pp. 156-172.

. (1994). Kinship with strangers: Adoption and Investigation of Kinship in American Culture. California: University of California Press.

Pena, Mariela (2014). "'Hacer las cosas bien'. Adopciones, parentesco y maternidad en los nuevos significados morales construidos desde el Estado". En: Tarducci, Mónica (comp.). Feminismo, lesbianismo y maternidad en Argentina. Buenos Aires, Librería de Mujeres Editoras.

. (2013). "El discurso 'psi' en el campo de la adopción. Posibilidades y límites frente al modelo de familia tradicional". Argonautas, no 3, pp. 31-55.

y Mónica Tarducci (2012). "Cuando lo público se resiste a ser político: Reflexiones sobre un grupo de 'padres' adoptivos en Internet". En: Debate Público, año 2, no 3, pp. 143-152.

Tarducci, Mónica (2012). "Las buenas y malas madres de la adopción". En Felitti (comp.) Maternidad en la Argentina actual. Buenos Aires: CICCUS, pp. 106-147.

. (2011). La adopción. Una aproximación desde la antropología del parentesco. Buenos Aires: Librería de Mujeres Editoras.

Thompson, Charis (2001). "Strategic Naturalizing: Kinship in an Infertility Clinic". En: Franklin, Sarah y Susan Mc Kinnon (eds.) Relative Values: Reconfiguring Kinship Studies. London: Duke University Press, pp. 175-202. 